\title{
Special Issue: Challenges for Europe 2050: Selected papers of the EUROFRAME Conference 2015 and the WWWforEurope Project
}

\author{
Michael Böheim ${ }^{1} \cdot$ Harald Oberhofer ${ }^{1,2}$
}

(C) Springer Science+Business Media New York 2016

The successful European model is undergoing a critical period. Major external and internal challenges call for a profound and coherent long-term strategy. However, heterogeneity and imbalances across member states, as well as misperceptions about policy goals, are hindering successful reforms, resulting in low dynamics, high unemployment and a loss of leadership in sustainability. Therefore, Europe needs a new common vision of its position in the globalised world.

The WWWforEurope project ${ }^{1}$ strived to develop such a vision, claiming wellbeing as the overarching benchmark of performance for Europe. It is rendered operational with three strategic goals: (1) economic dynamics, implying that more people profit from a broader set of economic achievements; (2) social inclusiveness entailing lower unemployment and lower income spreads, as well as an absence of conflicts; and (3) environmental sustainability, demanding respect for planetary limits and an absolute reduction of emissions and resource use.

Simultaneity between goals, the pursuit of high-road ambitions, and a two-stage implementation are the three guiding principles of a reform strategy. They imply respecting trade-offs and creating synergies, going for a quality strategy based on innovation and skills and, finally, bringing consumption and investment in line with existing capacities so as to reduce inherited unemployment, debt and income

\footnotetext{
1 http://www.foreurope.eu/.

$\bowtie$ Harald Oberhofer

Harald.Oberhofer@wifo.ac.at; Harald.Oberhofer@wu.ac.at

Michael Böheim

Michael.Boeheim@wifo.ac.at

1 Austrian Institute of Economic Research, Arsenal Object 20, 1030 Vienna, Austria

2 Department of Economics, Vienna University of Economics and Business, Welthandelsplatz 1, 1020 Vienna, Austria
} 
inequality in a first stage and in a second stage enable higher wellbeing based on lower growth.

WWWforEurope identified seven drivers of change that are essential to transition. These drivers are: redirecting innovation, increasing the dynamics by investing into change, welfare systems fostering social investment, a labour market improving skills and providing symmetric flexibility, a decoupling of labour and energy from economic output, a public sector halving labour taxes and, finally, a reformed financial sector aligned with wellbeing.

To implement the strategy, reform resistances have to be identified. Successful reforms have to be comprehensive and well-communicated. Reforms are easier to implement if they are bundled, if losers are partly compensated and if reform partners are taken on board. New actors and bottom-up processes should be given an important role in Europe's transition and should be integrated into reform processes. The success of the strategy should be continuously monitored using indicators.

A new strategy for Europe aims to achieve the three goals of economic dynamics, social inclusiveness and environmental sustainability. It follows three guiding principles and will unfold based on seven essential drivers of change. A successful transition will be facilitated by new processes and actors removing reform barriers, making the transition more likely this time.

The WWWforEurope synthesis report is based on over 160 scientific background papers (Aiginger 2016). A fine selection of these papers together with contributions from the Euroframe Conference 2015 on "Challenges for Europe 2050" 2 held in Vienna on 12 June 2015 build the core of this special issue in Empirica: Journal of European Economics.

This special issue contains six original research papers which are devoted to a status-quo analysis of economic and political causes and consequences of the slowdown of the European economy and proposals for (policy) measures and adjustments to successfully deal with the consequences of this slowdown as well as for re-accelerating economic growth in Europe.

The first paper co-authored by Friedrich Heinemann and Theocharis Grigoriadis (2016) develops a classification of obstacles to economic policy reforms based on economic, political economy and behavioural economic approaches in order to derive "reform ability profiles" for the EU member states. In a comparative macroeconomic analysis the authors identify important political and economic characteristics which are able to explain the high degree of reform resistance observed in the Southern EU member states including e.g., low effectiveness in poverty reduction and high intertemporal discounting and uncertainty avoidance. The comparative analysis is accompanied by a microeconometric investigation empirically exploiting heterogeneity in reform acceptance across individuals based on Eurobarometer survey data. The results from this empirical exercise highlight the explanatory power of the theoretically identified reform obstacles for European citizens' attitudes towards political reforms. The findings from this paper are of specific interest for policy makers as they can be considered as guidelines for increasing reform acceptance in the European electorate.

\footnotetext{
2 http://euroframe.org/conferences.html.
} 
In the second paper of this special issue, Bonfiglio et al. (2016) apply a multiregional Input-Output model in order to assess the growth and employment effects from the EU's Common Agriculture Policy (CAP) payments. Furthermore, based on various policy scenarios the authors investigate the redistributive impacts of potential CAP reforms. The multiregional framework allows to highlight that the welfare effects from CAP do not only depend on initial allocation but also on intersectoral and interregional linkages in economic activities. As a consequence the alternative policy scenarios indicate that CAP payments are less redistributive as commonly expected.

Relying on unique dataset for Swedish firms capturing the time period from 1997 to 2011, the paper entitled "The "sugar rush" from innovation subsidies-a robust political economy perspective" co-authored by Gustafsson et al. (2016), empirically investigates the impact of innovation subsidies for firm performance. The estimation results which are based on a causal treatment effects framework point to the absence of any positive long-run effects of such subsidies for the firm performance of the majority of treated firms. For the short-run the analysis identifies positive effects for human capital investments and productivity, where the latter is mainly materialized in small firms. Taking on a robust political economy perspective, the authors attribute to absence of positive long-run effects to the difficulty of acquiring correct information about the benefitting firms resulting in institutional problems for designing appropriate incentive mechanisms.

Michele Catalano and Emilia Pezzolla (2016) also take on a long-run view by focussing on the development of three large EU economies namely France, Germany, and Italy. They setup and apply an overlapping generation (OLG) model in order to investigate the interplay between financial integration, diverging labour productivity and the aging of the populations in the considered economies and explicitly account for the core-periphery structure relevant for studying transmission mechanisms within the EU. The long-run projections from the model suggest the highest but over time decreasing GDP growth rate for Germany which in turn finances the capital accumulation processes in France and Italy. At the end of the 2010s the financial trend might be reversed as Italy is likely to over-save due to a widening in the gap in human capital endowment and productivity growth relative to France and Germany. As a consequence this reversal might induce a reduction in physical capital accumulation and innovation in Italy. The resulting diverging growth developments could be mitigated by public debt consolidation policies if implemented by Italy alone.

The paper "Structural change and global value chains in the EU" authored by Stöllinger (2016) asks whether the ongoing process of concentration of manufacturing activity in a Central European core together with the increased importance of global value chains (GVCs) impacts the structural change dynamics observed in the EU. The main findings of the empirical analysis for the time period lasting from 1995 to 2011 suggest a non-linear relationship between structural change and integration into GVCs. Central European economies from the manufacturing core tend to change their production structure towards manufacturing industries when participating in GVCs while in the other EU member states GVC integration seems to accelerate the (already observable) deindustrialisation process. 
In the last contribution to the special issue, Thomas Leoni (2016) reviews the developments of the European welfare states over the last decades and identifies the main challenges national social systems are confronted with. Thereby, he highlights the shift in the risk structure of European societies commonly captured by what is labelled "new social risks" and which had been accommodated only partially and with a high degree of cross-country variation before the outbreak of the Great Recession. Against this backdrop, the paper further discusses in depth why social investment both as an analytical framework and as an emerging policy paradigm seems the most appropriate approach for framing the objectives that contemporary welfare states have to pursue. Finally, Thomas Leoni calls for a stronger anchoring of social investment strategies within the EU architecture and more coordinated actions and commitment from the member states in order to increase the effectiveness of social investment as policy paradigm.

The papers published in this special issue can only cover some dimensions of the challenges Europe is currently facing but are able to highlight some potential policy reforms necessary to bring the EU back to a higher and more sustainable growth path. Taking an overall perspective on the individual contributions, this special issue points to the crucial role of coordinated policy action especially in the interplay between national authorities and the supranational EU governing bodies. With Great Britain's majority vote for leaving the EU the political pressure to reform the Union has reached a new quality. The scientific insights from both the WWWforEurope project and Euroframe's last year's conference and its still ongoing activities provide many suggestions for transforming the EU in order to increase its resilience for the future. As editors of this special issue we hope that these proposals find their way into the political arena when it comes to the redesigning of the EU.

\section{References}

Aiginger K (2016) New dynamics for Europe: reaping the benefits of socio-ecological transition, synthesis report. http://www.foreurope.eu/index.php?id=859

Bonfiglio A, Camaioni B, Coderoni S, Esposti R, Francesco Pagliacci F, Sotte F (2016) Where does EU money eventually go? The distribution of CAP expenditure across the European space. Empirica. doi:10.1007/s10663-016-9354-2

Catalano M, Pezzolla E (2016) The effects of education and aging in an OLG model: long-run growth in France, Germany and Italy. Empirica. doi:10.1007/s10663-016-9351-5

Gustafsson A, Stephan A, Hallman A, Karlsson N (2016) The "sugar rush" from innovation subsidies: a robust political economy perspective. Empirica. doi:10.1007/s10663-016-9350-6

Heinemann F, Grigoriadis T (2016) Origins of reform resistance and the Southern European regime. Empirica. doi:10.1007/s10663-016-9342-6

Leoni T (2016) Social investment-a guiding principle for welfare state adjustment after the crisis? Empirica. doi:10.1007/s10663-016-9348-0

Stöllinger R (2016) Structural change and global value chains in the EU. Empirica. doi:10.1007/s10663016-9349-z 